${ }^{1}$ Centre for Health Economics, University of York, York

${ }^{2} \mathrm{UCLH} / \mathrm{UCL}$ Biomedical Research Centre, University College London Hospitals NHS Trust, London, and Department of Statistical Science, University College London

${ }^{3}$ Medical Research Council Biostatistics Unit, Cambridge

${ }^{4}$ Health Economics Research Group, Brunel University, London

${ }^{5}$ Department of Epidemiology and Public Health, University College London Medical School, London WC1E 6BT

Correspondence to:HHemingway h.hemingway@ucl.ac.uk

doi: 10.1136/bmj.39129.442164.55

\title{
Cost effectiveness of clinically appropriate decisions on alternative treatments for angina pectoris: prospective observational study
}

\author{
S C Griffin, research fellow, ${ }^{1}$ I A Barber, lecturer in medical statistics, ${ }^{2}$ A Manca, Wellcome Trust training \\ fellow in health services research, ${ }^{1} \mathrm{M}$ J Sculpher, professor of health economics, ${ }^{1} \mathrm{~S} G$ Thompson, professor of \\ medical statistics, ${ }^{3}$ M J Buxton, professor of health economics, ${ }^{4} \mathrm{H}$ Hemingway, professor of clinical \\ epidemiology 5
}

\section{ABSTRACT}

Objective To assess whether revascularisation that is considered to be clinically appropriate is also cost effective.

Design Prospective observational study comparing cost effectiveness of coronary artery bypass grafting, percutaneous coronary intervention, or medical management within groups of patients rated as appropriate for revascularisation.

Setting Three tertiary care centres in London.

Participants Consecutive, unselected patients rated as clinically appropriate (using a nine member Delphi panel) to receive coronary artery bypass grafting only $(n=815)$; percutaneous coronary intervention only $(n=385)$; or both revascularisation procedures $(n=520)$.

Main outcome measure Cost per quality adjusted life year gained over six year follow-up, calculated with a National Health Service cost perspective and discounted at 3.5\%/year. Results Coronary artery bypass grafting cost $£ 22000$ ( $€ 33000$; \$43000) per quality adjusted life year gained compared with percutaneous coronary intervention among patients appropriate for coronary artery bypass grafting only (59\% probability of being cost effective at a cost effectiveness threshold of $£ 30000$ per quality adjusted life year) and $£ 19000$ per quality adjusted life year gained compared with medical management among those appropriate for both types of revascularisation (probability of being cost effective 63\%). In none of the three appropriateness groups was percutaneous coronary intervention cost effective at a threshold of $£ 30000$ per quality adjusted life year. Among patients rated appropriate for percutaneous coronary intervention only, the cost per quality adjusted life year gained for percutaneous coronary intervention compared with medical management was $£ 47000$, exceeding usual cost effectiveness thresholds; in these patients, medical management was most likely to be cost effective (probability 54\%).

Conclusions Among patients judged clinically appropriate for coronary revascularisation, coronary artery bypass grafting seemed cost effective but percutaneous coronary intervention did not. Cost effectiveness analysis based on observational data suggests that the clinical benefit of percutaneous coronary intervention may not be sufficient to justify its cost.

\section{INTRODUCTION}

Guidelines based on clinical appropriateness criteria (optimising net benefits to health) are widely used to inform decisions about practice but are insufficient grounds for allocating healthcare resources. Although consensus exists that cost effectiveness analysis is needed to maximise the health gains achieved from a limited budget, how closely formally measured clinical appropriateness accords with cost effectiveness is not known. Population rates of coronary revascularisation, particularly percutaneous coronary intervention, ${ }^{1}$ have increased rapidly, but many influential trials report no cost data, ${ }^{2}$ analyse costs but not in relation to effectiveness, ${ }^{3}$ or report cost effectiveness but not in terms of quality adjusted life years. ${ }^{4}$ No three way randomised comparisons of the cost effectiveness of medical management, percutaneous management, and coronary artery bypass grafting exist. ${ }^{2}$ Most importantly, as clinical equipoise is seen as an ethical prerequisite of randomisation, patients considered clinically more suitable for one procedure than another are, generally, not included in trials.

We sought, therefore, to identify the cost effectiveness of treatments rated as clinically appropriate by a multidisciplinary panel. We studied three alternative management strategies for coronary disease: coronary artery bypass grafting, percutaneous management, and medical management. We used the RAND appropriateness method, ${ }^{5}$ which has been shown to be a prognostically valid method to determine the clinical suitability of unselected patients to have revascularisation, ${ }^{67}$ but without consideration of costs. A cost effectiveness analysis based on quality adjusted life years is suitable for comparing treatments that are expected to affect mortality, morbidity, or both and is the most suitable basis to inform decisions about the provision or reimbursement of healthcare technologies. ${ }^{8}$ 


\section{METHODS}

\section{Participants}

The appropriateness of coronary revascularisation (ACRE) cohort consists of consecutive patients, recruited without exclusion criteria, who had coronary angiography between 15 April 1996 and 14 April 1997 at three hospitals of one National Health Service trust in London. ${ }^{5}$ We identified 4121 patients and followed them for six years. Most patients had chronic coronary disease at baseline; only $6 \%$ were recruited during an admission with acute myocardial infarction. This economic evaluation focuses on the subgroup of 1740 patients rated as appropriate to have bypass surgery, percutaneous management, or both. Of these, we excluded 20 patients because they died without having revascularisation and no record of their intended management plan existed. All patients gave consent. ${ }^{5} \mathrm{~A}$ detailed technical report of the methods used for this six year analysis is available (www.york.ac.uk/inst/ che/staff/griffin.htm).

\section{Clinical appropriateness ratings}

Before recruitment of patients to the ACRE study, a nine member expert panel rated separately the clinical appropriateness of bypass surgery and percutaneous management in hypothetical patients for 985 specific clinical indications (based on the RAND-Delphi technique $^{9}$ ). Appropriateness was defined by clinical judgment, based on available evidence, that doing a procedure would be associated with more benefit than harm. Appropriateness ratings were assigned to ACRE participants on the basis of their individual clinical characteristics at the time of angiography to identify those patients who would benefit clinically from revascularisation. Details of these ratings have been reported previously. ${ }^{10}$ The ratings did not take account of patient preferences or cost considerations.

\section{NHS resource use and costs}

We adopted the cost perspective of the NHS and included the costs of bypass surgery, percutaneous management and angiography procedures (including hospital stay), drugs, admissions for chest pain, general practitioner visits, outpatient appointments, and visits to the emergency department. The occurrence of hospital admissions, their reasons, and lengths of stay came from the NHS-wide clearing service. Data on drugs at baseline and at one year and six year followups came from hospital case notes, general practitioners' and patients' questionnaires (response rate $85 \%$ at baseline, $77 \%$ at one and six years), and case notes after admissions for chest pain. Frequency of attendance in the previous year at a general practice, outpatient department, or casualty came from the patients' questionnaire. Unit costs came from previously published studies and published pricing lists for the United Kingdom. ${ }^{3112}$ Costs are reported in UK sterling (£), updated to $2003 / 4$ prices and discounted at $3.5 \%$ year. ${ }^{811}$
Outcomes and quality adjusted life years

More than $99 \%$ of the study sample were flagged with the UK Office of National Statistics, which notified us of dates of death. We ascertained acute non-fatal myocardial infarction through the NHS-wide clearing service and classified it according to recent criteria. ${ }^{13}$ As part of the six year questionnaire, patients completed the EQ-5D health related quality of life instrument, from which we derived utility scores. ${ }^{1415}$ Utilities represent quality weights for the calculation of quality adjusted survival; 1 corresponds to the highest degree of quality of life, and 0 is equivalent to dead. As we did not collect EQ-5D data at baseline and one year followup, we estimated utilities for these time points by using other variables on the patients' questionnaire to predict EQ-5D scores in a regression model. The variables used included the patient rated severity of angina symptoms, ${ }^{16}$ shortness of breath, and demographic factors. We calculated an estimate of quality adjusted survival for each patient by weighting their survival according to their quality of life. We discounted quality adjusted survival at a rate of $3.5 \%$ a year. ${ }^{8}$

\section{Statistical methods}

We analysed patients in three groups on the basis of their being rated clinically appropriate for bypass surgery only (that is, not for percutaneous management), for both procedures, or for percutaneous management only (that is, not for bypass surgery). Within the three groups, we compared those who had bypass surgery, those who had percutaneous management, and those who had neither type of revascularisation (medical management). These actual management groups are defined as the treatment received within one year of index angiography. For patients who died within one year without having a procedure, we used the intended management recorded at baseline as a proxy for actual management.

We used regression analyses with interaction terms to estimate the effect of actual management, by appropriateness category, on cost effectiveness (total costs and quality adjusted survival), presence of angina, and mortality at six years' follow-up. We adjusted analyses for the potential confounders in table 1, and additionally included baseline utility for adjustment of quality adjusted life years. ${ }^{17}$ Odds ratios for presence of angina at six years came from multiple logistic regression and hazard ratios for death from Cox regression. Regression of life years (cumulative survival) used an ordinary least squares approach. We analysed cost effectiveness by using seemingly unrelated regression, ${ }^{18}$ a multivariate regression technique that accounts for the potential correlation between costs and quality adjusted survival.

To compare the three management strategies, we used standard cost effectiveness decision rules. ${ }^{19} \mathrm{We}$ calculated the incremental cost effectiveness ratio comparing two management strategies, which represents the cost per quality adjusted life year gained by moving to a more costly, more effective method of management. To reflect uncertainty, we derived cost 
$\overline{\text { Table } 1 \text { | Baseline characteristics by appropriateness category. Values are numbers (percentages) }}$ unless stated otherwise

\begin{tabular}{|c|c|c|c|}
\hline $\begin{array}{l}\text { Baseline covariate (No } \\
\text { missing) }\end{array}$ & $\begin{array}{l}\text { Appropriate for CABG } \\
\text { only }(n=815)\end{array}$ & $\begin{array}{l}\text { Appropriate for both } \\
\qquad(n=520)\end{array}$ & $\begin{array}{l}\text { Appropriate for } \mathrm{PCl} \text { only } \\
\qquad(\mathrm{n}=385)\end{array}$ \\
\hline Mean (SD) age (years) & $63(9)$ & $59(9)$ & 59 (9) \\
\hline Male & $671(82)$ & $403(78)$ & $292(76)$ \\
\hline \multicolumn{4}{|l|}{ Ethnic group (141): } \\
\hline White & $623(83)$ & $396(84)$ & $303(85)$ \\
\hline Other & 130 (17) & $76(16)$ & $51(14)$ \\
\hline Previous CABG & $60(7)$ & $68(13)$ & $29(8)$ \\
\hline Previous $\mathrm{PCl}$ & $31(4)$ & $62(12)$ & $45(12)$ \\
\hline Previous MI & $371(46)$ & $268(52)$ & $207(54)$ \\
\hline Heart failure & $116(14)$ & $48(9)$ & $44(11)$ \\
\hline Previous stroke & $76(9)$ & $34(7)$ & $29(8)$ \\
\hline Diabetes & $130(16)$ & 69 (13) & $52(14)$ \\
\hline \multicolumn{4}{|l|}{ No of diseased vessels: } \\
\hline$\leq 1$ & $18(2)$ & $213(41)$ & $282(73)$ \\
\hline 2 & $106(13)$ & $263(51)$ & $79(21)$ \\
\hline 3 or left main stem & $691(85)$ & $44(8)$ & $24(6)$ \\
\hline Diffuse disease & $199(24)$ & $71(14)$ & $28(7)$ \\
\hline \multicolumn{4}{|l|}{ Left ventricular function (329): } \\
\hline Normal & $456(67)$ & $324(82)$ & $251(78)$ \\
\hline Impaired & $220(33)$ & 71 (18) & $69(22)$ \\
\hline $\begin{array}{l}\text { Mean (SD) Parsonnet operative } \\
\text { risk score }{ }^{37}\end{array}$ & $7.3(5.4)$ & $5.2(4.4)$ & $5.8(5.3)$ \\
\hline \multicolumn{4}{|l|}{ CCS score (362): } \\
\hline 0 (no angina) & $38(6)$ & $22(5)$ & $14(5)$ \\
\hline I-II (mild angina) & $179(27)$ & $97(24)$ & $76(25)$ \\
\hline III-IV (severe angina) & $437(67)$ & $282(70)$ & $213(70)$ \\
\hline
\end{tabular}

$\mathrm{CABG}=$ coronary artery bypass graft; $\mathrm{CCS}=$ Canadian Cardiovascular Society; $\mathrm{PCl}=$ percutaneous coronary intervention; $\mathrm{Ml}=$ myocardial infarction.

effectiveness acceptability curves showing the probability that each treatment is cost effective for a range of threshold amounts that the NHS would be willing to pay per quality adjusted life year. ${ }^{20}$ We have used a threshold of $£ 30000$ ( $€ 45000 ; \$ 58000)$ per quality adjusted life year in presenting the cost effectiveness results, on the assumption that the maximum incremental cost effectiveness ratio acceptable to the NHS lies between $£ 20000$ and $£ 40000$ per quality adjusted life year. ${ }^{21}$

We imputed missing data on length of stay and patient reported resource use (general practitioner visits, outpatient attendances, and visits to casualty) with simple ordinary least squares. In adjusted analyses, and when obtaining utilities, we used multiple imputation with chained equations. ${ }^{2223} \mathrm{We}$ created five imputation datasets to allow retention of between imputation variance in estimating standard errors. ${ }^{24}$

We used univariate sensitivity analyses to investigate assumptions about the need to adjust for the definition of actual management, the inclusion of patient reported resource use, the exclusion of hospital admissions for reasons unrelated to chest pain, and the differential timing of the one year patients' questionnaire (one year from revascularisation for percutaneous management and bypass surgery or one year from index angiography for medical management).

\section{RESULTS}

Baseline characteristics

Of the 1720 patients in the economic analysis, 815 $(47 \%)$ were rated as appropriate for bypass surgery only, $520(30 \%)$ were rated as appropriate for both procedures, and $385(22 \%)$ were rated as appropriate for percutaneous management only (table 1). The prevalence of current smokers was similar across the three appropriateness groups $(10 \%, 10 \%$, and 13\%). The severity of angina (Canadian Cardiovascular Society class) was also similar. Those rated as appropriate for bypass surgery tended to have a higher number of diseased vessels, higher prevalence of impaired left ventricular function, and higher operative risk scores. Single vessel disease was more common among patients rated as appropriate for percutaneous management only.

\section{Clinical outcomes}

Over the six year follow-up, 44\% (335/754) of patients initially treated with medical management and $26 \%$ (93/364) of those initially treated with percutaneous management went on to have additional revascularisation procedures; of those who initially had bypass surgery, further revascularisation was needed for only $4 \%$ (25/602) of patients. Angina was present in 55\% (560/ 1020) of patients at six years. Among patients rated as appropriate for bypass surgery, adjusted analyses showed a significantly raised odds of angina for those who had percutaneous management or medical management compared with those who had bypass surgery (table 2). A suggestion of similarly raised odds was apparent in patients suitable for percutaneous management who had medical management compared with those who had percutaneous management. Overall, $16 \%(277 / 1720)$ of patients died during follow-up. Adjusted analyses in the group appropriate for bypass surgery showed a raised risk of death for those who had medical management compared with bypass surgery or percutaneous management. Among the group rated appropriate for percutaneous management and bypass surgery, we found some evidence that the risk of death in patients who had percutaneous management or medical management was almost twice that in those initially treated with bypass surgery (table 2).

\section{Costs}

The costs of treating patients with medical management remained considerably lower than those for percutaneous management or bypass surgery (fig 1). In year one, the costs of medical management were 9 $12 \%$ of bypass surgery costs and those for percutaneous management were $43-50 \%$ of bypass surgery costs. By year six, these ratios rose to $43-50 \%$ for medical management and $78-82 \%$ for percutaneous management, primarily owing to the need for additional revascularisation procedures (table 2 ). Approximately $74 \%$ of percutaneous interventions involved one or more stents. The average unadjusted costs of each initial treatment strategy were, at baseline, $£ 12500$ for bypass surgery, $£ 5800$ for percutaneous 
Table 2 | Six year clinical outcomes by appropriateness category and actual management. Values are numbers (percentages) unless stated otherwise

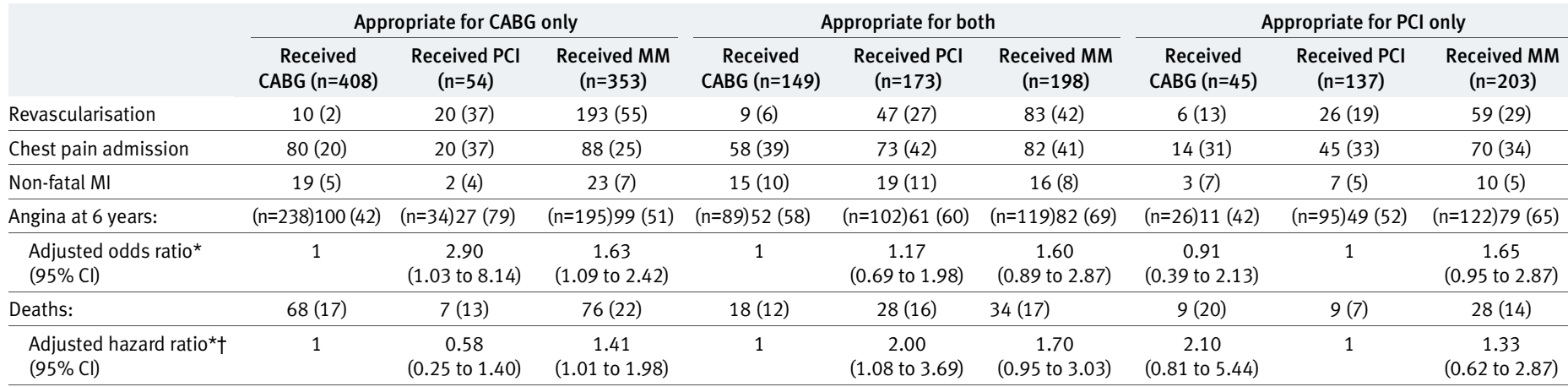

$\mathrm{CABG}=$ coronary artery bypass graft; $\mathrm{MI}=$ myocardial infarction; $\mathrm{MM}=$ medical management; $\mathrm{PCl}=$ percutaneous coronary intervention.

*Adjusted for age, sex, ethnic group, Canadian Cardiovascular Society score, left ventricular function, previous stroke, MI, previous CABG, previous PCI, diabetes, diffuse disease,

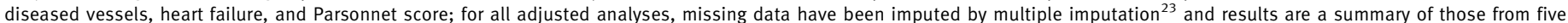

imputation datasets. ${ }^{24}$

†Overall hazard ratio presented despite some evidence of non-proportional hazards over time.

management, and $£ 1400$ for medical management; these rose to $£ 16200, £ 12100$, and $£ 9200$ at six years. The adjusted analysis made little difference to the estimated cost differences (table 3).

\section{Cost effectiveness}

Average predicted baseline utility was 0.55 , considerably lower than the UK population norm of 0.80 for people aged 55 to $64 . .^{25}$ The average utility score among those alive at six years improved to 0.65 . Because of deaths, the average length of survival in the study was around five years. Adjusted analyses by appropriateness category showed no significant differences in discounted mean survival duration (that is, life expectancy) across treatment groups. For the groups rated appropriate for bypass surgery only or percutaneous management only, the clinically appropriate treatment had the highest mean quality adjusted life years. In the group rated appropriate for either type of revascularisation, bypass surgery had the highest mean quality adjusted life years. Adjusted analyses showed significant differences in quality adjusted survival comparing medical management with bypass surgery in patients appropriate for bypass surgery only or for percutaneous management and bypass surgery (table 3).

Among patients rated as appropriate for bypass surgery only, the incremental analysis showed that percutaneous management had an incremental cost effectiveness ratio of $£ 11000$ per quality adjusted life year compared with medical management and bypass surgery had an incremental cost effectiveness ratio of $£ 22000$ per quality adjusted life year compared with percutaneous management (table 3 ). Thus bypass surgery is the most cost effective procedure for patients rated as appropriate for bypass surgery. The probability that bypass surgery is the most cost effective treatment strategy was $59 \%$ at a willingness to pay of $£ 30000$ per quality adjusted life year, compared with $40 \%$ for percutaneous management (fig 2).

In patients rated as appropriate for both procedures, percutaneous management was ruled out on grounds
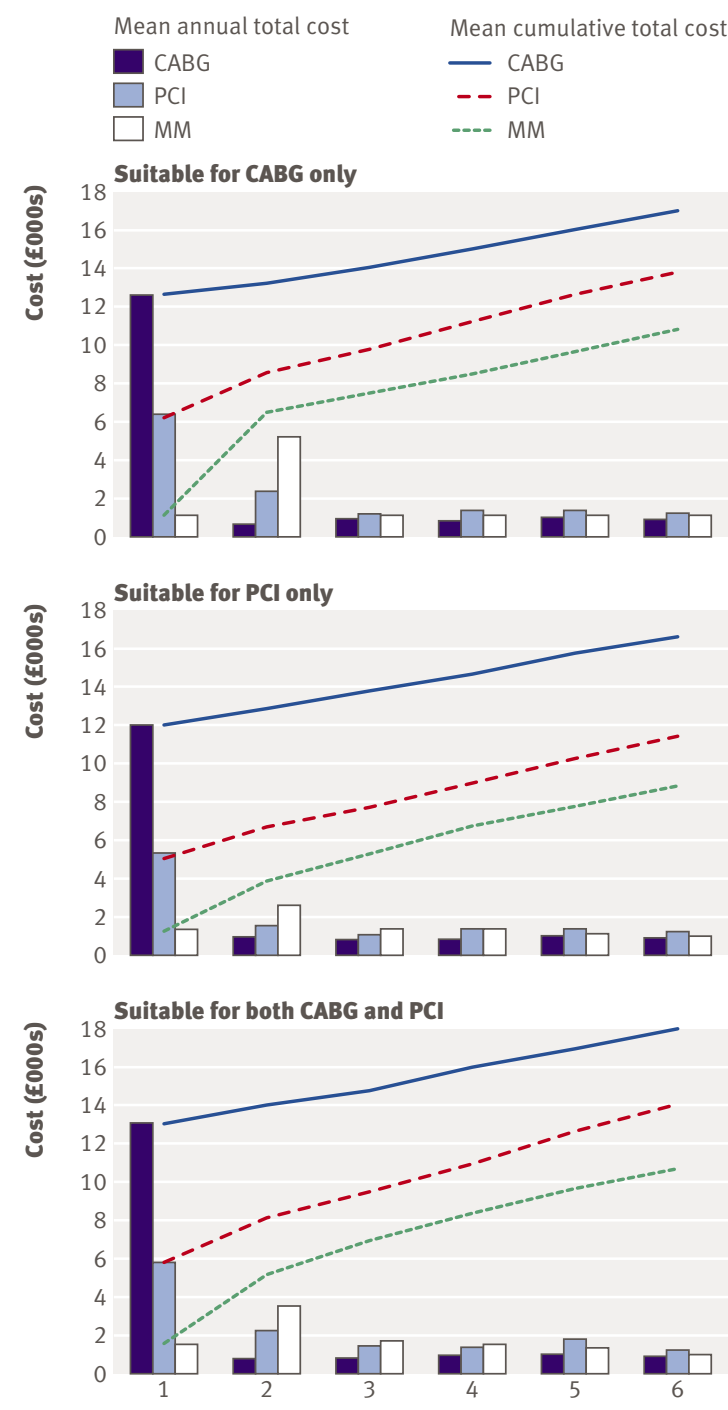

Yea

Fig 1 | Unadjusted total cost: mean annual and cumulative cost by actual management and appropriateness category. Costs presented in 2003/4 UK sterling, discounted at 3.5\% a year. $\mathrm{CABG}=$ coronary artery bypass surgery; $\mathrm{MM}=$ medical management; $\mathrm{PCl}=$ percutaneous coronary intervention 
Table 3 | Effectiveness and economic measures by appropriateness category and actual management. Values are mean (SD) unless stated otherwise

\begin{tabular}{|c|c|c|c|c|c|c|c|c|c|}
\hline & \multicolumn{3}{|c|}{ Appropriate for CABG only $(n=815)$} & \multicolumn{3}{|c|}{ Appropriate for both $(n=520)$} & \multicolumn{3}{|c|}{ Appropriate for $\mathrm{PCl}$ only $(\mathrm{n}=385)$} \\
\hline & $\begin{array}{l}\text { Received CABG } \\
\quad(n=408)\end{array}$ & $\begin{array}{c}\text { Received PCI } \\
\quad(n=54)\end{array}$ & $\begin{array}{l}\text { Received MM } \\
\quad(n=353)\end{array}$ & $\begin{array}{l}\text { Received CABG } \\
\quad(n=149)\end{array}$ & $\begin{array}{l}\text { Received PCI } \\
\quad(n=173)\end{array}$ & $\begin{array}{l}\text { Received MM } \\
\quad(n=198)\end{array}$ & $\begin{array}{l}\text { Received CABG } \\
\quad(n=45)\end{array}$ & $\begin{array}{l}\text { Received PCI } \\
\quad(n=137)\end{array}$ & $\begin{array}{l}\text { Received MM } \\
\quad(n=203)\end{array}$ \\
\hline $\begin{array}{l}\text { Utility at } \\
\text { baseline* }\end{array}$ & $\begin{array}{c}(n=281) \\
0.54(0.23)\end{array}$ & $\begin{array}{c}(n=35) \\
0.48(0.22)\end{array}$ & $\begin{array}{c}(n=262) \\
0.60(0.22)\end{array}$ & $\begin{array}{c}(n=94) \\
0.45(0.22)\end{array}$ & $\begin{array}{c}(n=120) \\
0.50(0.22)\end{array}$ & $\begin{array}{c}(n=145) \\
0.54(0.22)\end{array}$ & $\begin{array}{c}(n=33) \\
0.56(0.24)\end{array}$ & $\begin{array}{c}(n=96) \\
0.57(0.23)\end{array}$ & $\begin{array}{c}(n=148) \\
0.61(0.21)\end{array}$ \\
\hline Utility at 6 years* & $\begin{array}{c}(n=264) \\
0.69(0.29)\end{array}$ & $\begin{array}{c}(n=35) \\
0.61(0.36)\end{array}$ & $\begin{array}{c}(n=219) \\
0.67(0.31)\end{array}$ & $\begin{array}{c}(n=100) \\
0.66(0.31)\end{array}$ & $\begin{array}{c}(n=108) \\
0.65(0.30)\end{array}$ & $\begin{array}{c}(n=131) \\
0.61(0.30)\end{array}$ & $\begin{array}{c}(n=28) \\
0.69(0.28)\end{array}$ & $\begin{array}{c}(n=100) \\
0.65(0.29)\end{array}$ & $\begin{array}{c}(n=129) \\
0.66(0.29)\end{array}$ \\
\hline Life yearst: & $4.95(1.47)$ & $4.95(1.57)$ & $4.94(1.32)$ & $5.14(1.19)$ & $5.07(1.27)$ & $5.08(1.14)$ & $5.07(1.15)$ & $5.31(0.95)$ & $5.20(0.95)$ \\
\hline $\begin{array}{l}\text { Adjusted MD } \\
(95 \% \mathrm{Cl})\end{array}$ & $0 \ddagger$ & $\begin{array}{c}0.03 \\
(-0.32 \text { to } 0.39)\end{array}$ & $\begin{array}{c}-0.03 \\
(-0.21 \text { to } 0.15)\end{array}$ & $0 \ddagger$ & $\begin{array}{c}-0.17 \\
(-0.45 \text { to } 0.11)\end{array}$ & $\begin{array}{c}-0.09 \\
(-0.36 \text { to } 0.17)\end{array}$ & $\begin{array}{c}-0.13 \\
(-0.55 \text { to } 0.29)\end{array}$ & $0 \ddagger$ & $\begin{array}{c}0.06 \\
(-0.21 \text { to } 0.33)\end{array}$ \\
\hline QALYst: & $\begin{array}{c}(n=317) \\
3.29(1.55)\end{array}$ & $\begin{array}{c}(n=40) \\
3.01(1.54)\end{array}$ & $\begin{array}{c}(n=293) \\
3.02(1.53)\end{array}$ & $\begin{array}{c}(n=114) \\
3.13(1.37)\end{array}$ & $\begin{array}{c}(n=127) \\
2.93(1.65)\end{array}$ & $\begin{array}{c}(n=164) \\
2.83(1.39)\end{array}$ & $\begin{array}{c}(n=40) \\
3.08(1.59)\end{array}$ & $\begin{array}{c}(n=111) \\
3.31(1.47)\end{array}$ & $\begin{array}{c}(n=161) \\
3.15(1.43)\end{array}$ \\
\hline $\begin{array}{l}\text { Adjusted MD } \\
(95 \% \mathrm{Cl})\end{array}$ & $0 \ddagger$ & $\begin{array}{c}-0.15 \\
(-0.51 \text { to } 0.20)\end{array}$ & $\begin{array}{c}-0.40 \\
(-0.58 \text { to }-0.22)\end{array}$ & $0 \ddagger$ & $\begin{array}{c}-0.24 \\
(-0.52 \text { to } 0.04)\end{array}$ & $\begin{array}{c}-0.39 \\
(-0.70 \text { to }-0.09)\end{array}$ & $\begin{array}{c}-0.07 \\
(-0.50 \text { to } 0.37)\end{array}$ & $0 \ddagger$ & $\begin{array}{c}-0.06 \\
(-0.36 \text { to } 0.24)\end{array}$ \\
\hline Total cost $(£) \dagger$ : & $16980(7879)$ & $13875(7815)$ & $10850(7220)$ & $17859(6940)$ & 14007 (10 453) & $10690(7888)$ & $16541(5571)$ & $11493(6468)$ & $8775(7364)$ \\
\hline $\begin{array}{l}\text { Adjusted MD } \\
(95 \% \mathrm{Cl})\end{array}$ & $0 \ddagger$ & $\begin{array}{c}-3230(-5417 \text { to } \\
-1044)\end{array}$ & $\begin{array}{c}-5870(-6961 \text { to } \\
-4779)\end{array}$ & $0 \ddagger$ & $\begin{array}{c}-3820(-5510 \text { to } \\
-2130)\end{array}$ & $\begin{array}{c}-7255(-8875 \text { to } \\
-5636)\end{array}$ & $\begin{array}{c}4947(2359 \text { to } \\
7534)\end{array}$ & $0 \ddagger$ & $\begin{array}{c}-2847(-4510 \text { to } \\
-1184)\end{array}$ \\
\hline $\begin{array}{l}\text { ICERs ( } £ \text { per QALY) } \\
\text { (from adjusted } \\
\text { values) }\end{array}$ & $22000(v \mathrm{PCl})$ & $11000(v \mathrm{MM})$ & - & $19000(v \mathrm{MM})$ & ED & - & D & 47000 ( $v$ MM) & - \\
\hline \multicolumn{10}{|c|}{$\begin{array}{l}\text { CABG=coronary artery bypass graft; } P C l=\text { percutaneous coronary intervention; } D=\text { dominated; } E D=\text { ruled out by extended dominance; ICER=incremental cost effectiveness ratio (cost per } Q A L Y \\
\text { gained calculated in comparison with next relevant, less costly alternative }{ }^{19} ; M D=\text { mean difference; } M M=\text { medical management; QALY=quality adjusted life year. } \\
\text { *Includes values from prediction model as well as observed utility (for six year values only). } \\
\text { †Discounted at rate of } 3.5 \% \text { a year. } \\
\text { †Reference category. } \\
\text { Adjustments are for age, sex, ethnic group, Canadian Cardiovascular Society score, left ventricular function, previous stroke, myocardial infarction, previous CABG, previous PCI, diabetes, } \\
\text { diffuse disease, diseased vessels, heart failure, and Parsonnet score; adjusted analysis of QALYs and total cost are from seemingly unrelated regression and include an additional } \\
\text { adjustment for baseline utility; for all analyses missing data have been imputed by multiple imputation }{ }^{23} \text {; results are a summary of those from five imputation datasets. }{ }^{24}\end{array}$} \\
\hline
\end{tabular}

of "extended dominance"-at any cost effectiveness threshold, either medical management or bypass surgery was a more cost effective option (fig 2). The incremental cost effectiveness ratio for bypass surgery compared with medical management was estimated as $£ 19000$ per quality adjusted life year (table 3 ). The probability that bypass surgery, percutaneous management, and medical management are the most cost effective forms of management was estimated at $63 \%$, $22 \%$, and $15 \%$ respectively (fig 2 ).

Among patients appropriate for percutaneous management only, percutaneous management dominated bypass surgery (that is, it was less costly and more effective than bypass surgery) and had an estimated incremental cost effectiveness ratio of $£ 47000$ per quality adjusted life year compared with medical management (table 3). This incremental cost effectiveness ratio is above the maximum usually considered acceptable by the NHS, making medical management the most cost effective treatment strategy in patients rated as appropriate for percutaneous management. The probability that percutaneous management is most cost effective was estimated at 36\%, compared with 54\% for medical management (fig 2).

\section{Sensitivity analysis}

The cost effectiveness results were robust to adjustment for the timing of the one year questionnaire, the exclusion of patient reported cost data, and the inclusion of other hospital admissions. Altering the definition of actual management to treatment received within 15 months of angiography did not affect the study results. However, among the group rated as clinically appropriate for bypass surgery, altering the definition of actual management to treatment received within nine months caused the incremental cost effectiveness ratio for bypass surgery compared with percutaneous management to increase from $£ 22000$ to $£ 33000$.

\section{DISCUSSION}

Among consecutive patients, all of whom were judged to be clinically appropriate for revascularisation, the analysis suggests that bypass surgery within 12 months was cost effective in relation to a standard UK threshold but that percutaneous management was not. These findings challenge clinical practice and healthcare policy, which has evolved on a basis of evidence of effectiveness from clinical trials, largely in isolation from considerations of cost effectiveness. As angina pectoris has a high incidence and prognostic burden in the general population, where many patients are not evaluated for revascularisation, ${ }^{26}$ these findings are important for public health.

\section{Strengths and limitations}

This study has several strengths. Firstly, we defined clinical appropriateness by using an explicit method that has been shown to be highly reliable and prognostically valid. ${ }^{527}$ We used an expert panel to provide an independent measure of appropriateness, before recruitment of patients. Based on all forms of evidence-meta-analyses, ${ }^{28} 29$ trials, observational studies, and clinical experience - the panel's judgments aimed to articulate clinical appropriateness, without consideration of cost. 

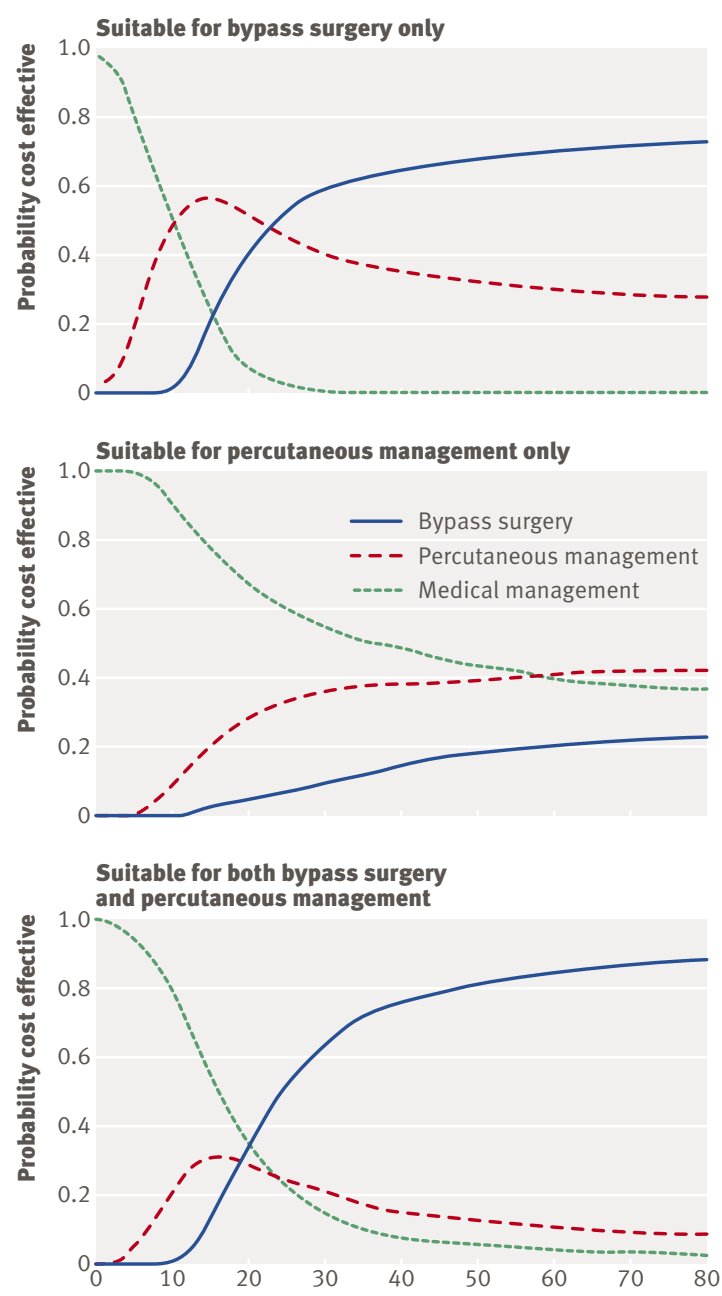

Threshold for cost effectiveness ( $£ 000 \mathrm{~s}$ )

Fig 2 | Cost effectiveness acceptability curves

Secondly, more than $90 \%$ of unselected consecutive patients were matched to an appropriateness rating, allowing our results to represent a real world view of cost effectiveness; patients selected into clinical trials may not be representative of unselected patients in terms of baseline severity of disease, health related quality of life, use of resources, and prognosis. ${ }^{30}$ The case fatality we observed in this population (approximately $3 \%$ a year) was comparable to that seen in large, less selected, primary care populations. ${ }^{26}$ Our analysis was made possible by the ubiquitous phenomenon that not all patients in whom revascularisation is deemed appropriate will actually receive it. We have shown that clinical appropriateness ratings in a broad unselected population accord with evidence of clinical effectiveness from trials.

Thirdly, we were able to make comparisons between three alternative management strategies that may never be simultaneously investigated in cost effectiveness analysis alongside randomised trials. This is both a strength and limitation; observational studies may be the only study design to answer the research question, but they come at a cost of confounding. Patients who go on to receive bypass surgery may have been destined to have better outcomes than those who do not, and the results may therefore be "confounded by indication." We sought to redress this both by design (patients who are judged to be suitable candidates for revascularisation are by definition more similar than those who are not) and by analysis (by using multivariate regression analysis to adjust for the potential confounding effects of baseline clinical and demographic characteristics).

A second limitation of our analysis, inherent in the need for long term follow-up studies, is that we do not know whether percutaneous management judged clinically appropriate according to the most recent criteria remains not cost effective. Although this awaits empirical testing, several lines of evidence indicate that this may be the case. The cost of the percutaneous management procedure has increased with drug eluting stents, ${ }^{31}$ and percutaneous management remains associated with higher costs resulting from subsequent admission to hospital. Meanwhile, an increasing number of drugs for secondary prevention have been shown to improve outcomes in chronic coronary disease.

\section{Association of clinical appropriateness with better outcomes}

Patients who had bypass surgery were least likely to have angina present at six years. This confirms findings from randomised trials, ${ }^{2-32}$ but in a broader, unselected population. The treatment rated as clinically appropriate corresponds with the greatest number of quality adjusted life years, although this result was statistically significant only for the comparison of medical management with clinically appropriate bypass surgery. Throughout the six year follow-up of this unselected patient group, quality of life remained lower than expected from age specific population norms. The low utility scores, despite intervention, reflect the findings of the bypass angioplasty revascularisation investigation (BARI) trial, in which angina was also found to have a substantial negative impact on quality of life. ${ }^{33}$

\section{Lack of cost effectiveness of percutaneous coronary intervention}

Our analysis indicates that clinically appropriate percu taneous management within 12 months was not cost effective. Despite the large increase in numbers of percutaneous coronary intervention procedures seen in many countries, we do not find this result surprising: the high costs of percutaneous management and the need for subsequent procedures, ${ }^{332}{ }^{34}$ absence of mortality benefit, ${ }^{35}$ and absence of a marked gain in quality of life have all been separately reported in trials. Our contribution is to estimate jointly the cost and outcome of percutaneous management that is considered clinically appropriate, in comparison with medical management and bypass surgery. The use of percutaneous management has increased rapidly, on the sole basis of clinical criteria without consideration of the economic consequences. As a result, the funds invested in percutaneous management could potentially be invested in more cost effective treatments that would provide greater benefit to NHS patients. 


\section{WHAT IS ALREADY KNOWN ON THIS TOPIC}

Guidelines based solely on clinical appropriateness are widely used to inform decisions about practice; whether care based on appropriateness criteria is also cost effective is unknown

No three way randomised comparisons of the cost effectiveness of medical management, percutaneous coronary intervention, and coronary artery bypass grafting have been done Evidence of cost effectiveness in "real world," routine practice settings is also lacking

\section{WHAT THIS STUDY ADDS}

Coronary artery bypass grafting seems both clinically beneficial and cost effective for patients judged clinically appropriate for revascularisation

The clinical benefit of percutaneous coronary intervention, however, does not seem to be sufficient to justify its additional cost
Contributors: All authors made substantial contributions to conception and design (health economic: MJS, MJB, SCG, and AM; statistical: SGT and JAB; clinical epidemiology: $\mathrm{HH}$ ) and analysis (SCG and JAB). All authors contributed to interpretation of data, drafting the article or revising it critically for important intellectual content, and final approval of the version to be published. $\mathrm{HH}, \mathrm{JAB}$, MJS, MJB, and SGT obtained funding. $\mathrm{HH}$ is the principal investigator on the ACRE study and is the guarantor. Adam Timmis contributed to the conception and design (clinical cardiology) and interpretation of data. Angela Crook and Roger Stafford prepared the data. Sue Philpott and Natalie Fitzpatrick were the project coordinators.

Funding: British Heart Foundation project grant. The British Heart Foundation had no role in study design; in the collection, analysis, and interpretation of data; in the writing of the report; or in the decision to submit the paper for publication. HH and MIS hold public health career scientist awards from the Department of Health. During the course of the ACRE cost effectiveness analysis study, AM became recipient of a Wellcome Trust training fellowship in health services research.

Competing interests: None declared.

Ethical approval: The five local ethics committees: West Essex, South Essex, Redbridge and Waltham Forest, East London and the City, and Barking and Havering.

Bypass surgery within 12 months was the most cost effective strategy among patients rated as appropriate to have bypass surgery if the maximum incremental cost effectiveness ratio the NHS is willing to accept is around $£ 30000$ per quality adjusted life year. However, if we define actual management as treatment received within nine months (which may be viewed as short given a mean UK waiting time of 6.5 months at the time of the study ${ }^{36}$ ) the incremental cost effectiveness ratio just exceeds $£ 30000$ per quality adjusted life year. We found that the relative cost differences between bypass surgery and percutaneous management reduced over the follow-up period, but the absolute difference remained significant at six years. Medical management is consistently the least costly form of management; the low treatment costs are not fully offset by high admission rates or costs of late procedures. Previous trials have indicated a greater degree of "catch up." The BARI trial showed an increase in percutaneous management costs from $65 \%$ to $98 \%$ of bypass surgery costs after 12 years of follow-up; most of the gain was in the first five years. ${ }^{33}$ Future work could extend the cost effectiveness model over a lifetime horizon, in which interventions with large "up-front" costs, such as bypass surgery, may seem more cost effective. Willingness to pay thresholds differ markedly across countries with the greatest numbers of people with chronic coronary disease-India, China, Russia, United States-and similar study designs could be used to inform national policies.

\section{Conclusion}

This cost effectiveness analysis in a real world setting offers a challenge to physicians, providers, and payers to show that the management of coronary disease currently offered, however clinically beneficial, is also cost effective. This was the case for bypass surgery within 12 months, but not for percutaneous management, for which the additional benefit was too small to justify the additional cost over the consistently less costly strategy of medical management.
1 Togni M, Balmer F, Pfiffner D, Maier W, Zeiher AM, Meier B, et al. Percutaneous coronary interventions in Europe 1992-2001. Eur Heart J 2004;25:1208-13.

2 Hueb W, Soares PR, Gersh BJ, César LAM, Luz PL, Puig LB, et al. The medicine, angioplasty, or surgery study (MASS-II): a randomized, controlled clinical trial of three therapeutic strategies for multivessel coronary artery disease. J Am Coll Cardiol 2004;43:1743-51.

3 Sculpher MJ, Smith DH, Clayton T, Henderson R, Buxton MJ, Pocock SJ, et al. Coronary angioplasty versus medical therapy for angina. Eur Heart J 2002;23:1291-300.

4 Claude J, Schindler C, Kuster GM, Schwenkglenks M, Szucs T, Buser $P$, et al. Cost-effectiveness of invasive versus medical management of elderly patients with chronic symptomatic coronary artery disease: findings of the randomized trial of invasive versus medical therapy in elderly patients with chronic angina (TIME). Eur Heart / 2004;25:2195-203.

5 Brook RH, Chassin MR, Fink A, Solomon DH, Kosecoff J, Park RE. A method for the detailed assessment of the appropriateness of medical technologies. Int J Technol Assess Health Care 1986;2:53-63.

6 Hemingway H, Crook A, Feder G, Banjeree S, Dawson J, Magee P, et al. Underuse of coronary revascularization procedures in patients considered appropriate candidates for revascularization. $N$ Engl J Med 2001;344:645-54.

7 Kravitz RL, Laouri M, Kahan JP, Guzy P, Sherman T, Hilborne L, et al. Validity of criteria used for detecting underuse of coronary revascularization. JAMA 1995;274:632-8.

8 National Institute for Clinical Excellence. Guide to the methods of technology appraisal. London: NICE, 2004.

9 Bernstein SJ, Laouri M, Hilborne LH, Leape LL, Kahan JO, Park RE, et al. Coronary angiography: a literature review and ratings of appropriateness and necessity. Santa Monica, CA: RAND, 1992.

10 Hemingway H, Crook AM, Dawson JR, Edelman J, Edmondson S, Feder G, et al. Rating the appropriateness of coronary angiography, coronary angioplasty and coronary artery bypass grafting: the ACRE study. I Public Health Med 1999;21:421-9.

11 Netten A, Curtis L. Unit costs of health and social care. Canterbury: Personal Social Services Research Unit, University of Kent, 2004.

12 British Medical Association, Royal Pharmaceutical Society of Great Britain. British national formulary. London: BMA, RPS, 2004. (No 48.)

13 Joint European Society of Cardiology/American College of Cardiology Committee. Myocardial infarction redefined-a consensus document of the Joint European Society of Cardiology/American College of Cardiology Committee for the Redefinition of Myocardial Infarction. Eur Heart J 2000;21:1502-13.

14 Kind P. The EuroQoL instrument: an index of health-related quality of life. In: Spilker B, ed. Quality of life and pharmacoeconomics in clinical trials. 2nd ed. Philadelphia: Lippincott-Raven, 1996.

15 Dolan PG, Kind P, Williams A. A social tariff for EuroQol: results from a UK general population survey. York: Centre for Health Economics, University of York, 1995.

16 Campeau L. Grading of angina pectoris. Circulation 1976;1976:522-3.

17 Manca A, Hawkins N, Sculpher MJ. Estimating mean QALYs in trialbased cost-effectiveness analysis: the importance of controlling for baseline utility. Health Econ 2005;14:487-96.

18 Willan AR, Briggs AH, Hoch JS. Regression methods for covariate adjustment and subgroup analysis for non-censored costeffectiveness data. Health Econ 2004;13:461-75. 
19 Johannesson M, Weinstein S. On the decision rules of costeffectiveness analysis. J Health Econ 1993;12:459-67.

20 Fenwick E, Claxton K, Sculpher M. Representing uncertainty: the role of cost-effectiveness acceptability curves. Health Econ 2001;10:779-89.

21 Raftery J. NICE: faster access to modern treatments? Analysis of guidance on health technologies. BMJ 2001;323:1300-3.

22 Royston P. Multiple imputation of missing values. Stata Journal 2004; 4:227-41.

23 Van Buuren S, Boshuizen HC, Knook DL. Multiple imputation of missing blood pressure covariates in survival analysis. Stat Med 1999;18:681-94.

24 Rubin DB. Multiple imputation for nonresponse in surveys. New York: John Wiley \& Sons, 1987.

25 Kind P, Hardman G, Macran S. Centre for Health Economics discussion paper 172: UK population norms for EQ-5D. York: Centre for Health Economics, University of York, 1999.

26 Hemingway H, McCallum A, Shipley M, Manderbacka K, Martikainen P, Keskimäki I. Incidence and prognostic implications of stable angina pectoris among women and men. JAMA 2006;295:1404-11.

27 Shekelle PG, Kahan JP, Bernstein SJ, Leape LL, Kamberg CJ, Park RE. The reproducibility of a method to identify the overuse and underuse of medical procedures. N Engl J Med 1998;338:1888-95.

28 Pocock SJ, Henderson RA, Rickards AF, Hampton JR, King SB 3rd, Hamm CW, et al. Meta-analysis of randomised trials comparing coronary angioplasty with bypass surgery. Lancet 1995;346:1184-9.

29 Yusuf S, Zucker D, Peduzzi P, Fisher LD, Takaro T, Kennedy JW, et al. Effect of coronary artery bypass graft surgery on survival: overview of 10-year results from randomised trials by the coronary artery bypass graft surgery trialists collaboration. Lancet 1994;344:563-71.
30 Krumholz HM, Peterson ED, Ayanian JZ, Chin MH, DeBusk RF, Goldman L, et al. Report of the National Heart, Lung, and Blood Institute Working Group on Outcomes Research in Cardiovascular Disease. Circulation 2005;111:3078-86.

31 Kaiser C, Rocca B-L, Buser P, Bonetti PO, Osswald S, Linka A, et al. Incremental cost-effectiveness of drug-eluting stents compared with a third-generation bare-metal stent in a real-world setting: randomised Basel stent kosten effektivitäts trial (BASKET). Lancet 2005;366:921-9.

32 Bypass Angioplasty Revascularization Investigation (BARI) Investigators. Five-year clinical and functional outcome comparing bypass surgery and angioplasty in patients with multivessel coronary disease: a multicenter randomized trial. JAMA 1997;277:715-21.

33 Hlatky MA, Boothroyd DB, Melsop KA, Brooks MM, Mark DB, Pitt B, et al. Medical costs and quality of life 10 to 12 years after randomization to angioplasty or bypass surgery for multivessel coronary artery disease. Circulation 2004;110:1960-6.

34 Hill RA, Bagust A, Bakhai A, Dickson R, Dündar Y, Haycox A, et al. Coronary artery stents: a rapid systematic review and economic evaluation. Health Technol Assess 2004:8:1-256.

35 Bucher H, Hengstler P, Schindler C, Guyatt GH. Percutaneous transluminal coronary angioplasty versus medical treatment for nonacute coronary heart disease: meta-analysis of randomised controlled trials. BMJ 2000;321:73-7.

36 Hospital Episode Statistics. Main operations: summary, England, N HS Hospitals, 1998-99. www.hesonline.nhs.uk.

37 Parsonnet $\mathrm{V}$, Dean D, Bernstein AD. A method of uniform stratification of risk for evaluating the results of surgery in acquired adult heart disease. Circulation 1989;79:I-3-I-12.

Accepted: 23 January 2007 